\title{
Discussion on the Simulation Training Thought of Helmsman Manipulation Skill Training Course
}

\author{
Haipeng Zhang*, Xiangpeng Zhang, Xiao Zhang, Xiayu Ai \\ Navy Submarine Academy \\ Qingdao, Shandong Province, P. R. China, 266000 \\ E-mail: fdrk02@163.com
}

\begin{abstract}
In order to improve the teaching effect of the ship Skill Training Course of Helmsman Manipulation, meanwhile based on the characteristics of the training course of helmsman manipulation skills, this paper analyzed impact of the simulation training thoughts on the helmsman manipulation skills training, furthermore, conducted the study on the main problems facing by helmsman manipulation on training and teaching activities, this paper also analyzed the skill training course of Helmsman Manipulation's simulation training performance, has designed the simulation training function of Skill Training Course of Helmsman Manipulation, proposed several thoughts on applying simulation training ideas in the manipulation of skills. Generally, this paper offers a reformation concept for the training of the Skills Training Course of Helmsman Manipulation and provides a reference in aspects of cultivating advanced talents and promoting modernization.
\end{abstract}

Keywords—simulation training; helmsman manipulation; ship; skill training

\section{INTRODUCTION}

Helmsman Manipulation is an important skill training course in professional learning processes such as ships, ships and submarines[1], because the traditional Master's skill training methods and methods cannot meet the requirements of modern education, the use of advanced training methods and scientific training methods is an important factor to ensure the effectiveness of the Helmsman Manipulation training program [2]. Generally speaking, simulation training has become a common measure and an important means to improve the quality of training in vocational education institutions in various countries [3-5]. It is of great significance to apply the advanced techniques, means and equipment, and to apply the simulation training ideas to the teaching, training, assessment and evaluation of the Skill Training Course of Helmsman Manipulation.

Based on the characteristics of Skill Training Course of Helmsman Manipulation, this paper analyzes the impact of simulation training on Helmsman Manipulation skill training, and studies the main problems currently faced by Helmsman Manipulation skill training, and then analyze the simulation of Skill Training Course of Helmsman Manipulation. Based on the training effectiveness, the simulation training function of Skill Training Course of Helmsman Manipulation was designed. Finally, some thoughts on applying the simulation training thought in the manual skill training were expounded.

\section{CHARACTERISTICS ANALYSIS OF HELMSMAN MANIPULATION SKILL TRAINING COURSE}

Helmsman Manipulation means that the manipulator achieves the purpose of flexible maneuvering of the ship by controlling and manipulating the ship. The manipulating movement refers to the change of the state of motion caused by the operation of the manipulator, and manipulating is one of the performances of the ship. Helmsman Manipulation is a skill-based training course. For skill-based training, the common traditional teaching methods are mainly: by the master, the apprentice learns the same, and then relies on a lot of training for a long time to form muscle memory. This teaching method is inefficient and the teaching methods are backward, and the teaching effect is usually poor.

The teaching characteristics of Helmsman Manipulation courses for ships, ships, submarines, etc. are: it can build a complete training and evaluation feedback system like car driving training, and it can only be learned during the skill training process like riding a bicycle with unspeakable features. The overall teaching objectives of the Helmsman Manipulation course generally include learning: basic concepts, basic theories, manipulating methods of rudders in various subjects, force analysis of rudders, and state prediction of ships.

The basic idea of Helmsman Manipulation course teaching is that it should adhere to the teaching philosophy of "guided practice by theory and practice test theory". The Helmsman Manipulation course and teaching ideas are: The benign cycle teaching principle of "learning- practice - assessment feedback - retraining" should be implemented in a practical way. It is a skill-generating process that focuses on the helmsman manipulation of ships and requires repeated practice to form experience and feel. In addition, the comprehensive use of multiple teaching links and a variety of teaching methods, making full use of a variety of teaching methods to achieve the desired teaching results.

\section{THE IMPACT OF SimUlation TRAINING ON HELMSMAN MANIPULATION SKILLS TRAINING}

At present, with the improvement of simulation technology and the improvement of simulation methods, the development technology of simulation training system is constantly developing and mature. The ideas and methods of simulation training have been widely used in various military and civil sector skills training, such as submarines. Maneuvering, aviation aircraft driving, nautical ships and car driving. 


\section{The Actual On-ship Training Task is Often Impossible to be Completed}

As the internship time, route, navigation area and other conditions are limited by the tasks undertaken by the traineeship, many of the prescribed internship projects may not be completed in accordance with the requirements, and even some projects cannot be completed at all. Be more specific, much professional knowledge cannot be verified in the practice of navigation, the effect of navigation internship is not obvious, failed to achieve the intended purpose.

\section{The difficulty of Internship Management}

After the student went to the internship ship, due to a large number of people on board, the internship management brought great difficulties. The internship project was limited due to the number of people and limited internship time. The trainee itself was responsible for the task, and some internship projects were subject to the impact of the voyage was not completed and the good navigational internship effect was not achieved. The students of some institutions are assigned to the ships. After boarding the ship, they mainly rely on the captains, drivers or old sailors on the trainees. Some of them have a poor cultural level and weak guidance ability, which cannot complete the task; The connection between the teacher and the student is only transmitted by telephone or through the internship unit. The cost is high, and on-site guidance cannot be achieved. It is difficult to achieve targeted, which leads to a decrease in the quality of the internship.

\section{E. Intensive Training Time and Low Training Efficiency}

The core post personnel often have many things and heavy tasks and cannot participate in the training. As a result, the normalized job rotation training becomes "out of tolerance" and "shift". So that most of the current talent training still stays in the simple post-based study, relying on this level of training, relying on the traditional model of the side, has not been liberated from the scattered training of "zero-breaking" and "small-small”. However, the training techniques are single, and the advanced training methods such as simulation training system, computer technology, simulation technology and network simulation technology are not fully utilized, and the training benefits are still relatively low.

\section{F. Insufficient Training Equipment in Colleges and Institutions}

In the process of practice, the cultivation of talents in China has been continually explored, and the division of hierarchy and rank has been initially established, and the job-based training has been gradually promoted. However, the definition of the training objectives of talents at different levels and levels is often unclear and not fine. Therefore, the operability of the training plan is poor. In addition, because the talents at all levels may have a vague concept of their own knowledge, ability, and quality requirements, they cannot form conscious behaviors in the specific practice stage, which leads to the use of learning, the disjunction of training, the repetition of training content, and the unclear target level. As a result; in addition, lack of advancement, training is still at a low level of proficiency and experience. More importantly, job orientation education is not targeted, and generally focuses on theoretical 
learning and lacks practical training. At the same time, there are also many other unreasonable factors. For example, the teaching and training facilities of colleges and universities are out of touch with new equipment. The training materials and job requirements are out of line. The connection between colleges and universities is not close, and the quality of training is relatively slow.

\section{ANALYSIS OF SimUlation TRAINING EFFECT OF HELMSMAN MANIPULATION SKILL TRAINING COURSE}

\section{A. Systematic Simulation Analysis of Helmsman Manipulation}

"Ship Manipulation Dynamics Simulation" is a mathematical model that describes the movement of a ship's manipulation. It uses the computer's motion model of the ship to solve the position of the model and the state of the motion in time series to obtain various motion parameters of the ship. Then, by real-time display on the computer, the various functions performed on the control device simulate and reproduce the ship's response to the external environment interfering with various operations. Specifically, the operations performed on the control device mainly include: manual steering, automatic steering, and other operations similar to the ship's bridge; the external environment mainly includes wind, water, waves, waterways, etc.; the response aspect of the ship It mainly includes dynamic information such as the position, heading, heel, trim, first rudder angle and tail rudder angle of the ship. The "Manipulation Dynamics Simulation System" can simulate the movement of the ship under water and the whole process of guidance, thus giving people a more intuitive and more vivid understanding. The key to the fidelity of the "Manipulation Dynamics Simulation of Ships" is to establish accurate ship motion models and to choose the correct solution method.

\section{B. Analysis of Systematic Simulation Technology}

"Systematic Simulation Technology" is a multidisciplinary comprehensive technology based on the theory of "similarity theory", "control theory", "information processing technology" and related fields of applied technology, and then computer and Various simulators and special physical effect devices are used as tools, and the system model is used to test real or imaginary systems, and the test results are analyzed and analyzed by means of statistical data and information materials, so as to finally make a decision.

Systematic simulation consists of three basic elements: the system, the system model, and the computer (both hardware and software). The general steps of system simulation are shown in Fig. 1. In the actual simulation, it is necessary to make corresponding changes in light of the actual situation.

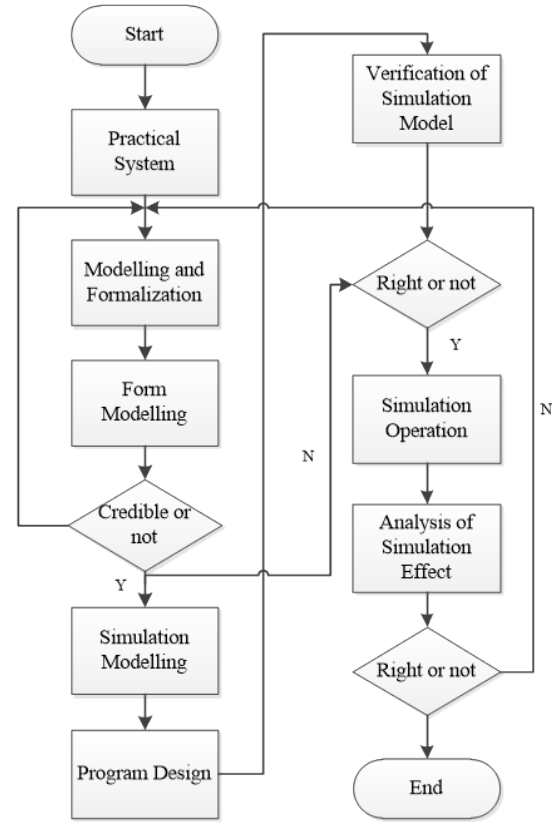

Fig. 1. General steps for system simulation

\section{Analysis of Simulation Training Characteristics}

\section{1) Complete simulation training function}

The actual navigation mission of the ship under high-tech conditions puts higher requirements on the training ground and training environment. The simple use of the sea training method cannot meet the training requirements, and it is difficult to achieve the expected training effect. By establishing a dedicated training base (center), you can take advantage of simulation training. These centers usually have a full range of functions and a comprehensive training venue with large-scale simulated training facilities for training. Through the base-based synthetic training method, it is possible to obtain better training effects in a small amount of time and in a short time.

\section{2) Controllable simulation training process}

The simulation training method not only solves the difficult problems encountered in practice, but also has the advantages of shortening the training time, controlling the training of the trainees, and being able to perform repeated training. In addition, slow motion and computer printout can be used. The way to analyze and study the training of the students.

\section{3) Realistic simulation training environment}

Using a variety of simulation equipment, not only can realistically simulate various training states, but also provide realistic environments and conditions for repeated drills. Now, the main sign of the "training revolution" that is being promoted and implemented abroad is to strengthen the reform and application of the simulation training system. The establishment of a large number of simulation training systems not only saves a lot of training funds, but also can carry out advanced training drills for some difficult to preview or potentially dangerous plans. 
personnel, especially the common knowledge defects of the training personnel who can't form a historical database and a syndrome database. In fact, this wastes valuable historical experience, which makes it impossible for coaches to effectively grasp the key points and difficult contents in the training process, and cannot conduct targeted analysis and comment. network to conduct distributed and interactive network training.

\section{5) Embedded training of virtual and real}

The Embedded training system can be configured at the same time as the equipment, providing full-time, all-round and uninterrupted training conditions, which can effectively improve students' ability to respond to emergencies. The purpose of Embedded Simulation (ES) and Embedded Training (ET) is to improve students' operational ability through efficient, low-cost, and realistic training. In terms of equipment, the embedded simulation technology system is to integrate the physical structure and functional performance into the equipment system. It is worth emphasizing that the simulation technology system cannot be operated independently of the equipment system, and belongs to the intelligent components of the equipment system. The operation of the simulation system must support, match and coordinate with the real equipment system.

\section{Design of Simulation Assessment FunCtion of SKILl TRAINING COURSE HELMSMAN MANIPULATION}

\section{A. Helmsman Manipulation simulator evaluation system problem}

However, there are some problems in the examination and evaluation of the Helmsman Manipulation simulation system. The main reasons for this are:

- The simulator operation process is complicated, and the evaluation system is not standard, and the assessment and evaluation of the trainers' lack of flexibility. In addition, the judgment of the operation results of most simulators is determined by the teacher according to the operation process of the trainers. Therefore, it is difficult to make a reasonable and scientific judgment on the training process and the effects of the trainers.

- During the training process, it must rely on the teacher's on-site guidance. In detail, in the specific training process, the trainers do not have clear questions; the trainers cannot get effective help through the system itself. In addition, the system does not give guidance and advice to the trainer during the practice.

- Lack of proper training methods. Especially for the training according to the strict operation of the program, since the coach cannot control the operation process of each person from time to time, the training cannot achieve the purpose, and the training personnel are not standardized.

- Lack of commentary and analysis on the major and difficult issues in training. There is no effective statistics on the operation assessment of each training

\section{B. Examination and evaluation system design ideas}

The scoring standard of the simulator should be very objective and optimal, so it is necessary to design a training scoring system combining subjective and objective. The system should be used to record the training personnel's operation records and the system's calculated standard answers. Compare, so as to give assessment results and improvement suggestions. The exam and assessment system should have the following features:

- Intelligent tutor function: including the system can provide multimedia teaching function for trainees, can give the reasonable explanation and answer to the problems encountered by trainers in operation, and strengthen the training of trainers in a targeted manner.

- Project selection function: Set and select the exams and assessment subjects that meet the teaching needs.

- Scientific and practical scoring function: In the test and evaluation system, the system can provide real-time interpretation mechanism and final evaluation results according to the students' operation. The interpretation mechanism is an integral part of the expert scoring system, which makes the evaluation process and evaluation criteria transparent, thereby enhancing the reliability of the evaluation. This function not only requires the scoring system not only to give students the assessment results, but also to give students the lack of performance and existing knowledge defects in the operation process.

- Statistical analysis function: It can count the training situation of each examination and evaluation project, and form a statistical database of training scores and common mistakes, so as to play a reference and promote the future training work.

- $\quad$ Recording and printing functions: The training process can be played back and recorded.

VII. REFLECTIONS ON THE APPLICATION OF SIMULATION TRAINING IN THE MANIPULATION SKILLS TRAINING ACTIVITIES

\section{A. Building up an advanced technology platform and build a} large-scale training center

The development of modern society requires high-quality talents, and high-quality talents need advanced training platforms. It is necessary to change the traditional forms of warfare, break through the pattern of "passing the band" , break the boundaries of units, departments and regions, implement complementary advantages, and establish an 
integrated and large-scale simulation training base and simulation center.

With the development of economy and science and technology, it is possible to develop a training simulation system that matches modern society and form a large-scale simulation training center. New technologies such as computer simulation, virtual reality, and distributed interactive simulation should be fully utilized to build a networked simulation training system and an intelligent intensive training platform to cultivate knowledge-based, intelligent, and composite talents.

\section{B. Established leading standards and regulations to achieve the development of training equipment specifications}

At present, many overseas countries attach great importance to the formulation of military standards such as simulation training and interactive simulation. This situation makes the relevant research and development units have laws to follow in the establishment of the project. We should gradually establish a system of national standards and military standards for simulation training systems, and clarify that the development of simulation training systems must be based on uniform standardized development standards. We should focus on research and development of hardware, software systems that are portable, easy to upgrade and system interoperability, and realize the standardized and standardized development path of “one type and multiple changes” and "interconnected”.

\section{Implement top-level design planning and promote the embedded training system}

The well-trained crew, effective coordination of various departments, complex and proper handling of emergency situations are the key factors for ship safety and successful mission completion. These can all be achieved through daily simulation training. However, due to the frequent execution of sea missions, the departure of warship personnel and the constraints of training funds, it is difficult for the ship to send the crew off the post and go to the training base to participate in simulation training such as training classes and training courses. If the skilled individual training and the coordinated training of the department for the purpose of cooperation are placed on a ship, it will not hinder the completion of the daily mission of the ship, and can also meet the staffing of the ship. The requirements have also met the basic training objectives of novice skilled equipment and coordination. Therefore, the development of the embedded simulation training system and the introduction of the Embedded training system design in the ship design phase through the top-level design have very practical significance.

\section{CONCLUSION}

The development of the future society requires more high-quality talents. High-quality talents cannot be separated from high-performance talent training activities. This paper explores the advanced simulation training ideas in Helmsman Manipulation talent training. Based on the characteristics of the training course for Helmsman Manipulation skills, this paper analyzes the impact of simulation training ideas on Helmsman Manipulation skills training, and studies the current training of Helmsman Manipulation skills training. The main problem is the analysis of the simulation training effectiveness of the Helmsman Manipulation skill-training course. The simulation training function of the Skill Training Course of Helmsman Manipulation is designed. Finally, some thoughts on applying the simulation training thought in the training of skills are expounded. Generally, China's modernization is undergoing a leap-forward development process, which requires us to look to the world, carry out strategic transformation in the reform of the education model, cultivate a comprehensive quality and compound knowledge structure, and have a scientific spirit of innovation and innovation. The ability of new talents, and thus continue to promote modernization.

\section{REFERENCES}

[1] Huang Yongfeng. "Modeling of Ship Hydraulic Steering Gear System and Its Intelligent Cloud Model Control[D]”. Dalian Maritime University. 2018. (In Chinese)

[2] Yin Xulin. "From the training of foreign military officers to see the transformation of talent training in our army[J]". Journal of Air Force Radar Academy, 2006, 20(2): 154-156. (In Chinese)

[3] Zhang Peifan. "Simulation Study of Flight Simulator Training System [D]”. Harbin Engineering University. 2016. (In Chinese)

[4] Ren Jiezeng. "Foreign Military Simulation Training Organization [J]". Foreign tanks, 1997, 02: 35-40. (In Chinese)

[5] Conrad G B, Brian F, LCDR S K, et al. Dutch Space and NLR deliver F-35 Embedded Training System to Lockheed Martin[J]. International Journal of Artificial Intelligence in Education, 2009, 10(8): 25-29.

[6] Wang Wenwu, Zhao Lin, Hao Yanling, Yang Shuguo. "Design of Ship Navigation Training Simulator Based on VR.” Journal of System Simulation. 2009, 13(3): 599-601, 614. (In Chinese) 